\title{
Cerebral palsy-is it a seasonal disorder?
}

\author{
LALIT KANT, SAROJINI DEWAN, AND B K JAIN \\ From the Department of Preventive and Social Medicine, Maulana Azad Medical College, New Delhi, India
}

SUMMARY A relationship between the season of birth and the occurrence of neurological disorders has already been reported. An attempt has been made to see if a similar relationship exists in the case of cerebral palsy also. The month of birth of all the 212 children with cerebral palsy attending specialised centres in New Delhi was ascertained. The month of birth was compared with the month-wise normal distribution of live births in Delhi. The difference in monthly trend was found to be statistically highly significant. Does it suggest that cerebral palsy is a seasonal disorder?

Our concept of the epidemiology of cerebral palsy has not changed much in the last 122 years. In 1862 , Little proposed abnormal parturition and asphyxia neonatorum as a cause of cerebral palsy. Since then until the present day many more explanations have been floated but few have held water for long.

As happens with any disorder with poorly understood aetiological factors, in the case of cerebral palsy the epidemiologist would search for an association between environmental factors and the disorder. The month of birth is one such factor.

The effect of climatic changes on man's health was first studied in detail by Hippocrates ${ }^{1}$ and has been comprehensively reviewed by Tromp. ${ }^{2}$ For diseases of early life, such as cerebral palsy, variation in risk by season or month of birth may point to the existence of environmental influences acting during intrauterine or very early postnatal life and give hints as to their nature.

A study was undertaken to find the relationship, if any, between the month of birth and the occurrence of cerebral palsy in children. To our knowledge, no such observation has been reported in the literature.

\section{Material and method}

Parents of all the 212 children with cerebral palsy attending specialised centres in New Delhi were contacted personally, and the month of birth of the affected child was recorded irrespective of age. These parents were contacted at the Department of Physical Medicine and Rehabilitation, Kalawati Saran Children's Hospital, New Delhi and at the Centre for Special Education run by the Spastics Society of India, New Delhi branch.

\section{Results}

All the children had been born in the Union Territory of Delhi. Their month of birth as recorded is given in the table. A sharp rise in the number of births is seen in August. The rise continues in September and reaches a peak in October, falling steadily in November and December.

As the seasonal trends in normal live births do not change appreciably from year to year, for the purpose of comparison month-wise live births in the Union Territory of Delhi in 1979 are used. The null hypothesis that the cerebral palsy cases occur equally in relation to the number of live births during a year was tested using the $\chi^{2}$ test, and a statistically highly significant difference in monthly trends is seen $\left(\chi^{2}=30 \cdot 38 ; \mathrm{df}=11 ; \mathrm{p}<0 \cdot 01\right)$, thus rejecting the null hypothesis.

Month-wise distribution of live births in Delhi and of children with cerebral palsy

\begin{tabular}{lcc}
\hline Month & $\begin{array}{l}\text { Live births in } \\
\text { Delhi }(1979)^{3}\end{array}$ & $\begin{array}{l}\text { Number of cases of } \\
\text { cerebral palsy }\end{array}$ \\
\hline January & 9809 & 11 \\
February & 8508 & 10 \\
March & 8263 & 8 \\
April & 7438 & 6 \\
May & 9901 & 8 \\
June & 7677 & 9 \\
July & 11437 & 12 \\
August & 17324 & 29 \\
September & 15343 & 32 \\
October & 18176 & 44 \\
November & 13941 & 29 \\
December & 14900 & 14 \\
Totals & 142797 & 212 \\
\hline
\end{tabular}

$\chi^{2}=30 \cdot 3844 ; \mathrm{df}=11 ; \mathrm{p}<0 \cdot 01$. 


\section{Discussion}

New Delhi is situated at a latitude of $28^{\circ} 39^{\prime} \mathrm{N}$ and a longitude of $77^{\circ} 13^{\prime} \mathrm{E}$. The climate is essentially tropical. The year is usually divided into the cold season (December, January), spring (February, March), summer (April, May, June), rains (July, August), and autumn (September, October, November). Unlike the temperate regions there is an unequal distribution of months among the seasons. In this study the births have been categorised month-wise rather than according to the season.

There is a remarkable seasonal trend in total live births in Delhi, with an approximately twofold increase when comparing October to April (table). Also, referring to the month-wise distribution of the live births for the past 30 years in Delhi, it is evident that the maximum number of births occur between August and October and the minimum number between February and June, ${ }^{3}$ indicating that the conception rate is lowest between May and September-the hot and humid months-and highest between December and February-the cool and festive months. This variation is consistent from year to year.

During the summer months the temperature soars to above $40^{\circ} \mathrm{C}$ and the humidity during the rains is over $95 \%$. There is little need to suppose that the decreased conception rate during the hot season is due to physiological depression of the reproductive organs, and it would be reasonable to ascribe it to a lower coital rate resulting from heat fatigue and a distaste for personal contact during hot weather.

With the onset of autumn there is a fall in the temperature and an increase in festivities. Gradually the winter sets in and the cool and crisp air requires that people sleep indoors, providing better opportunities for more intimate behaviour. Better climatic conditions coupled with a mood of convivial merry-making set the stage for a higher rate of conception.

Similar seasonal variations in normal live births have been observed all over the world. ${ }^{4}$ The peaks and troughs differ according to the geographical and cultural milieu of each country.

Our data are biased with respect to living children with cerebral palsy. The health information system in India is still in its infancy. Though the law requires that all births and deaths be registered, not all are reported. The death forms are incomplete and even those that are complete are of poor credibility. Hence it is difficult to know the cause of death, the social group and the number of children who would have died due to cerebral palsy or associated conditions.

It has also been assumed that the children studied form a representative sample. Apart from the two centres where the study was conducted, no other institution in Delhi deals with children with cerebral palsy. One of the centres (Kalawati Saran Children's Hospital) is run by the Government and is free for all. The other (Centre for Special Education), a private body, charges for services. As the facilities are available to all, irrespective of their capacity to pay for the rehabilitation, it has been assumed that the children attending these centres come from all social classes and ethnic groups.

In the present study, conducted in New Delhi, it was observed that a large number of children with cerebral palsy were born between August and November, with a peak in October. To test the seasonality of a disorder non-parametric and other tests are available, ${ }^{56}$ but due to limited resources the best choice we had was the $\chi^{2}$ test. The difference in the months of births of children with cerebral palsy compared to normal live births has been found to be highly significant. These findings present certain possibilities:

1 Harmful influences may affect gestation which begins in December-March and ends between August and November.

2 Cerebral palsy may be related to yet unidentified nutritional disturbances in pregnancy which may be caused by changes in the maternal diet during the hot summer months.

3 A rise in the incidence of tropical disease (especially febrile illness and diarrhoeal diseases and the attendant dehydration) during the summer and the rainy months may have a detrimental effect on the fetus.

It may be too early to come to a conclusion. In spite of the shortcomings the observations do point to a possible association unnoticed until now. More studies on a wider scale and in different geographical areas are needed to draw a meaningful conclusion.

Address for correspondence and requests for reprints: Dr Lalit Kant, B-95, Gulmohar Park, New Delhi, India 110049.

\section{References}

${ }^{1}$ Kelly EC. Translation of Hippocrates: airs, waters and places. In: Medical classics. Baltimore: Williams and Wilkins, 1938, Vol 3; 19.

${ }^{2}$ Tromp SW. Medical biometeorology, weather, climate and the living organism. Amsterdam: Elsevier, 1963.

${ }^{3}$ Annual Reports 1951-80, Bureau of Economics and Statistics, Delhi Administration, Delhi.

${ }^{4}$ Parkes AS. Patterns of sexuality and reproduction. London: Oxford University Press, 1976.

${ }^{5}$ Hewitt D, Milner J, Csima Adele, Pakula Andrew. On Edwards' criteria of seasonality and non-parametric alternative. Br J Prev Soc Med 1971; 25: 174-6.

${ }^{6}$ Walter SD, Elwood JM. A test for seasonality of events with a variable population at risk. Br J Prev Soc Med 1975; 29: 18-21. 